\title{
Ultrastructure and Function of Alveolar Macrophages from Cystic Fibrosis Patients
}

\author{
MARY JANE THOMASSEN, ${ }^{(22)}$ CATHERINE A. DEMKO, ROBERT E. WOOD, BERNARD TANDLER, \\ DORR G. DEARBORN, BERNARD BOXERBAUM, AND PAULA J. KUCHENBROD \\ Departments of Pediatrics, Microbiology, and Biochemistry, Rainbow Babies and Childrens Hospital, School of \\ Medicine, and Department of Oral Biologv, School of Dentistrv, Case Western Reserve University. Cleveland, Ohio.
}

\section{Summary}

\begin{abstract}
Alveolar macrophages were isolated from three cystic fibrosis patients, and the structure and function of these cells were compared to that of normal alveolar macrophages. The cystic fibrosis (CF) and normal alveolar macrophages were able to phagocytize Pseudomonas in the presence of normal serum, but cells from both sources had decreased phagocytosis of Pseudomonas in the presence of CF serum. Phagocytosis of Staphylococcus was not inhibited. Ultrastructural studies showed $C F$ macrophages to be morphologically normal, however, in contrast to CF polymorphonuclear cells, they had not been heavily engaged in phagocytosis. The similarities between $\mathrm{CF}$ and normal macrophages suggest that the chronic pulmonary infection of CF may be due to an extrinsic factor in an altered lung environment rather than to any intrinsic cellular defect of the alveolar macrophage.
\end{abstract}

\section{Speculation}

Functional and morphologic observations indicate that cystic fibrosis alveolar macrophages are not providing an adequate phagocytic defense against Pseudomonas. This defective phagocytosis does not appear to arise from an intrinsic problem with the macrophages, but rather appears to be due to extrinsic factors, i.e., an altered lung environment together with a substance(s) present in cystic fibrosis serum which selectively inhibit Pseudomonas phagocytosis.

Chronic bronchial infection and associated airway obstruction are major factors in the pathophysiology of cystic fibrosis (CF) (2). Although pulmonary infection with Staphylococcus aureus often occurs, Pseudomonas aeruginosa eventually emerges as the dominant pathogen in the majority of CF patients (20). The reason for the predominance of this organism is unknown. The alveolar macrophage has been shown to be important in the defense of the lung against bacterial invasion (5). Although it originates from the same stem cell as the other phagocytic cells, the function of the alveolar macrophage is more susceptible to impairment by environmental conditions, such as lowered oxygen tension, that do not affect the other phagocytes (1).

Previously, we reported the presence in CF serum of an inhibitory activity against the phagocytosis of Pseudomonas by rabbit and normal human alveolar macrophages (17). Phagocytosis of $S$ aureus and of Serratia marcescens, another gram-negative organism. was unaffected by this activity. Clinical condition and Pseudomonas agglutinating antibody titer did not correlate with the presence of the activity. Chronic Pseudomonas infection did not appear to be a necessary prerequisite, but the presence of the inhibitory activity usually correlated with a positive Pseudomonas culture history.

In the present study, the structure and function of CF alveolar macrophages was investigated and compared to normal alveolar macrophages. Experimental observations are presented which suggest that the $C F$ alveolar macrophage is intrinsically normal but that it may be affected by extrinsic factors present in the CF lung.

\section{MATERIALS AND METHODS}

All studies were carried out under an approved human investigation protocol and after securing informed consent from all participants.

\section{PREPARATION OF ALVEOLAR MACROPHACIES}

Alveolar macrophages were obtained from normal, healthy adult volunteers by fiberoptic bronchoscopy as previously described (17).

The CF patients serving as cell donors are described below.

CF 1 is a $7 \frac{1}{2}$-year-old girl with mild manifestations of pulmonary involvement (vital capacity $96 \%$ of predicted: physical examination normal; chest X-ray score, 20/25). She was found to have atelectasis of the lateral segment of the right middle lobe on a routine chest film. She underwent therapeutic bronchoscopy and was found to have scant secretions in the airways. Lavage of the right middle lobe with $450 \mathrm{ml}$ of saline yielded only a few mucus plugs. The patient had cultured nonmucoid Pseudomonas on only two occasions prior to lavage.

CF 2 is a $131 / 2$-year-old girl with moderate manifestations of pulmonary involvement (vital capacity $66 \%$ of predicted; diffuse rales and rhonchi on physical examination; chest X-ray score. 15/ 25 ). She developed increased cough and on a chest film was found to have right middle lobe atelectasis. Therapeutic lavage of the right middle lobe with I liter of saline yielded large amounts of mucopurulent secretions and mucus plugs. One wk later, the right middle lobe was again lavaged with $800 \mathrm{ml}$ of saline. Much less mucopurulent material and fewer plugs were obtained with the second procedure. The patient had consistently cultured mucoid Pseudomonas for seven years prior to the lavage.

CF 3 is a 17 -year-old man with moderate pulmonary involvement [vital capacity, $100 \%$ of predicted, forced expiratory volume in $1 \mathrm{sec}\left(\mathrm{FEV}_{1}\right) 66 \%$ of vital capacity; diffuse rales and rhonchi on physical examination; chest X-ray score, 14/25]. He underwent therapeutic lavage of his right upper lobe with 1.5 liters of normal saline. Large amounts of mucopurulent material and bronchial casts were found in the lavage fluid. The patient had consistently cultured mucoid Pseudomonas for three years prior to the lavage.

CF 4 is a 17 -year-old man with severe pulmonary involvement (vital capacity, $40 \%$ of predicted: $\mathrm{FEV}_{1}, 40 \%$ of vital capacity; arterial $\mathrm{PO}_{2}$ consistently less than 40 ; little air exchange on physical examination; and chest X-ray score, 6/25). He underwent therapeutic bronchopulmonary lavage on repeated occasions, at which time massive quantities of thick mucopurulent secretions were noted in the airways. Large amounts of mucopurulent material and bronchial casts were removed at each lavage. The patient had consistently positive sputum cultures for mucoid Pseudomonas during the seven years prior to the lavages. 
CF 5 is a 28-year-old man with severe but predominantly rightsided pulmonary involvement (vital capacity $60 \%$ of predicted: $\mathrm{FEV}_{1}, 50 \%$ of vital capacity; diminished breath sounds with very coarse rales and rhonchi on the right but normal breath sounds on the left; and chest X-ray score, 14/25). A xenon perfusionventilation scan revealed virtually no perfusion or ventilation of the entire right hemithorax. This patient underwent massive bronchopulmonary lavage to the right lung on repeated occasions for therapeutic purposes. Large amounts of mucopurulent secretions and bronchial casts and plugs were removed at each occasion. The patient had mucoid Pseudomonas at the onset of care at this institution immediately prior to the lavages.

The lung washings from both normal volunteers and $C F$ patients were passed through a blood filter (Travenol Laboratories, Inc., Deerfield, IL), and centrifuged at $400 \times g$ for $10 \mathrm{~min}$, whereupon the cell pellet was washed three times with normal saline. A small portion of this pellet was washed in $0.1 \mathrm{M}$ phosphate buffer ( $\mathrm{pH} 7.8$ ) and processed for electron microscopy. The pellets were resuspended in a volume of saline sufficient to achieve a uniform density. Seven $\mathrm{ml}$ of this suspension containing approximately $1 \times 10^{7}$ cells were placed on $3 \mathrm{ml}$ of a Ficoll-Hypaque gradient (Pharmacia Fine Chemicals, Piscataway, N. J.) and centrifuged at $400 \times g$ for $40 \mathrm{~min}$. The cells at the interface were removed, washed with saline, and counted with a Coulter counter model $Z_{\mathrm{f}}$ (Coulter Electronics, Inc., Hialeah, FL). Differential cell counts were done with either tetrachrome stain or nonspecific esterase stain (9). Cultures stained by the former method were photographed in a Zeiss Ultraphot II. Viability was evaluated by trypan blue dye exclusion.

\section{ESTABLISHMENT OF MACROPHAGE CULTURES}

Macrophages were cultured in tissue culture chambers (2- or 4chamber units; LabTek Products Div., Miles Laboratories, Inc., Naperville, IL) containing McCoy's 5A medium (Grand Island Biological Co., Grand Island, N. Y.) supplemented with $10 \%$ heatinactivated fetal calf serum, L-glutamine, $(2.9 \mathrm{mg} / \mathrm{ml})$ and antibiotics [gentamicin sulfate $(0.1 \mathrm{mg} / \mathrm{ml})$, penicillin $(100 \mathrm{units} / \mathrm{ml})$, streptomycin $(100 \mu \mathrm{g} / \mathrm{ml})$, and amphotericin B $(0.25 \mu \mathrm{g} / \mathrm{ml})]$. CF macrophage cultures were also supplemented with the following amounts of antibiotics: tobramycin $(0.1 \mathrm{mg} / \mathrm{ml})$, colistin $(1.1 \mathrm{mg} /$ $\mathrm{ml})$, and amphotericin B $(1.25 \mu \mathrm{g} / \mathrm{ml})$. The two-chamber slides were seeded with approximately $1 \times 10^{\text {fi }}$ macrophages per chamber, and the four-chamber slides were seeded with $5 \times 10^{5}$ cells per chamber (21). CF cultures were all washed with Hanks' balanced salt solution (BSS) 30 to $60 \mathrm{~min}$ after seeding to remove mucus particles which remained in suspension while the macrophages were firmly attached to the glass surface. Cultures were incubated for 24 to $48 \mathrm{hr}$ at $37^{\circ} \mathrm{C}$ in a humidified $5 \% \mathrm{CO}_{2}$ atmosphere. To ensure comparability of cell cultures, individual cultures were checked for uniformity of the cell population by examination with an inverted microscope at $\times 100$, and those that were not comparable were discarded.

\section{PREPARATION OF RADIOACTIVE BACTERIA}

A clinical isolate of $P$. aeruginosa [Fisher type 1 (4), Homma type 8 (7)] was labeled with ['H]leucine (specific activity, 30 to 50 $\mathrm{Ci} / \mathrm{mmole}$ : ICN Pharmaceuticals, Inc., Irvin, CA), and an isolate of $S$. aureus was labeled with [" $\mathrm{H}$ ]thymidine (specific activity, 40 to $60 \mathrm{Ci} / \mathrm{mmole}$, Amersham/Searle Corp., Arlington Heights, IL) as described previously (14). These two isolates were used for all the experiments.

\section{SERUM SAMPLES}

Ten to $30 \mathrm{ml}$ of blood were obtained from each subject. After clotting at room temperature, the blood was centrifuged at 1500 $\times g$ and the serum was decanted. The serum was then aliquoted and, if not used immediately, was stored at $-70^{\circ} \mathrm{C}$. In some experiments, pooled normal human sera (Grand Island Biological
Co.) were used as controls. As described in the previous report (17), the CF serum donors were classified into three categories: good, moderate, and poor clinical condition. This classification was based on a modification (3) of the Shwachman and Kulczycki system (14) and pulmonary function tests. As before, these donors were preselected on the basis of being able to be taken off antibiotics for $48 \mathrm{hr}$ prior to blood drawing. Samples used were also selected on the basis of previous results in phagocytosis assays using rabbit alveolar macrophages (17). The 24- to 48-hr macrophage monolayer cultures were washed three times with BSS before adding the reaction mixture, which consisted of $0.1 \mathrm{ml}$ of $1: 1$ dilution of a CF or a normal serum sample in BSS, $0.1 \mathrm{ml}$ of the bacterial suspension (the specific activity of the bacteria was always greater than $10^{-4} \mathrm{cpm}$ per bacterium), and $0.8 \mathrm{ml}$ of BSS. All components were preincubated individually at $37^{\circ} \mathrm{C}$. The ratio of bacteria to cells varied between $10: 1$ and 100:1. The exact number of bacteria used in each experiment was determined by plate counts from dilutions of the original bacteria inoculum. The variation in the ratio of bacteria to cells over this range did not affect the comparison of phagocytosis in the presence of $C F$ and normal serum because the ratio was constant within each experiment. The experiments were performed in parallel, i.e.. each assay included duplicate tests of both CF and normal serum samples. The chambers were incubated at $37^{\circ} \mathrm{C}$ with gentle shaking for 30 min, whereupon the supernatant was decanted, and the cell layer was washed six times with cold BSS. One $\mathrm{ml}$ of cold distilled water was then added to each culture to lyse the cell monolayer. The cells were allowed to swell for at least $30 \mathrm{~min}$ in the cold and then disrupted by vigorous pipetting. Observations of the culture vessels with an inverted microscope $(\times 100)$ routinely revealed all the cells to be disrupted by this procedure. One-tenth $\mathrm{ml}$ of the lysate was then counted in Triton X-100 toluene scintillation fluid. Calculations were as follows

$$
\begin{aligned}
& \frac{\mathrm{cpm} \text { in lysate from each culture }}{\mathrm{cpm} \text { of bacteria added to each culture }} \times 100=\% \text { phagocytosis } \\
& {\left[\begin{array}{r}
\left.1-\frac{\% \text { phagocytosis }(\mathrm{CF} \text { serum })}{\% \text { phagocytosis (control serum) }}\right] \\
\times 100=\% \text { inhibition of phagocytosis }
\end{array}\right.}
\end{aligned}
$$

For statistical evaluation, the paired $t$ test was used to compare the percentage of phagocytosis in the presence of CF serum to the percentage of phagocytosis in the presence of normal control serum.

\section{ELECTRON MIC ROSCOPY}

Pellets of cells were fixed at room temperature for $2 \mathrm{hr}$ in halfstrength Karnovsky's (8) fixative buffered with phosphate. After rinsing in buffered sucrose, they were postfixed for $2 \mathrm{hr}$ in phosphate-buffered $2 \%$ osmium tetroxide (10). The pellets were briefly rinsed in distilled water, soaked overnight in cold $0.25 \%$ aqueous uranyl acetate, and once again rinsed in distilled water. Dehydration in ascending concentrations of ethanol and passage through propylene oxide were followed by embedment in Epon-Maraglas (16). Thin sections were stained sequentially in methanolic uranyl acetate (15) and lead tartrate (11) and examined with a Siemens Elmiskop la electron microscope.

\section{RESULTS \\ CF LAVAGE FLUID}

The lavage fluid varied considerably from patient to patient. Table 1 shows the cellular composition and viability of the cells from the fluid of the five patients. The three patients in better clinical condition (CF-1, CF-2, and CF-3) had greater percentages of macrophages, whereas the two patients in poorer clinical condition (CF-4 and CF-5) had virtually no macrophages. Both of these patients had minimal lung function in the area lavaged. The 
viability of the macrophages from patients 1 and 2 was not determined at the time of isolation, but the viability of the cultured population at the time of the assay was $>99 \%$. Pseudomonas was cultured fom the lavage fluid of all patients. This was unexpected in CF-I because previous sputum cultures taken the same wk had not demonstrated Pseudomonas.

\section{FICOLL-HYPAQUE GRADIENT}

Ficoll-Hypaque gradients were used for the separation of mononuclear leukocytes (lymphocytes and macrophages) from polymorphonuclear cells (PMN's) and other lavage fluid debris. In general, macrophages remained at the interface of the gradient. However, especially in highly viscous lavage fluids, some of the macrophages became entrapped in the debris and mucus and

Table 1. Composition of lavage fluid

\begin{tabular}{ccrcc} 
Patient & $\begin{array}{c}\% \text { alveolar } \\
\text { macrophage }\end{array}$ & $\begin{array}{r}\% \\
\text { PMN }\end{array}$ & $\begin{array}{c}\% \\
\text { viability }\end{array}$ & $\begin{array}{c}\text { Pseudomonas } \\
\text { present in fluid }\end{array}$ \\
\hline CF-1 & $>90$ & $<10$ & $N^{t}$ & + \\
CF-2 & 39 & 60 & ND & + \\
CF-3 & $50^{2}$ & 50 & 78 & + \\
CF-4 & $<1$ & $>99$ & ND & + \\
CF-5 $_{\text {Average }}$ & $<1$ & $>99$ & $>95$ & + \\
control $^{-1}$ & 89 & $<1$ & $>95$ & - \\
\hline
\end{tabular}

${ }^{1}$ Not done.

${ }^{2}$ Many degenerating cells were present on the smear, making exact quantitation difficult.

${ }^{3}$ Average of 10 controls.

Table 2. Effect of Ficoll-Hypaque gradient on Pseudomonas phagocytosis by normal alveolar macrophages ${ }^{t}$

\begin{tabular}{|c|c|c|c|c|}
\hline \multirow[b]{2}{*}{$\begin{array}{l}\text { Serum } \\
\text { source }\end{array}$} & \multicolumn{2}{|c|}{ Before gradient } & \multicolumn{2}{|c|}{ After gradient } \\
\hline & $\mathrm{cpm}^{2}$ & $\begin{array}{c}\% \\
\text { phagocytosis }^{3}\end{array}$ & $\mathrm{cpm}^{2}$ & $\begin{array}{c}\% \\
\text { phagocytosis }\end{array}$ \\
\hline $\mathrm{CF}$ & 566 & 4.7 & 420 & 3.5 \\
\hline Control & 1535 & 12.8 & 1564 & 13.0 \\
\hline
\end{tabular}

' All assays were carried out with $1 \times 10^{6}$ macrophages.

${ }^{2} \mathrm{cpm}$ in $0.1 \mathrm{ml}$ aliquot of $1.0 \mathrm{ml}$ lysate.

"Percentage of radioactive organisms engulfed in $30 \mathrm{~min}$ (see "Materials and Methods" for details). sedimented to the bottom of the gradient. Some mucus remained at the interface but was later removed during culture. We did not detect an appreciable number of lymphocytes in the lavage fluid: the few that remained in the interface were eventually removed from the macrophage cultures due to their lack of adherence. After $24 \mathrm{hr}$ in culture, the CF cells (Fig. 1) were predominately
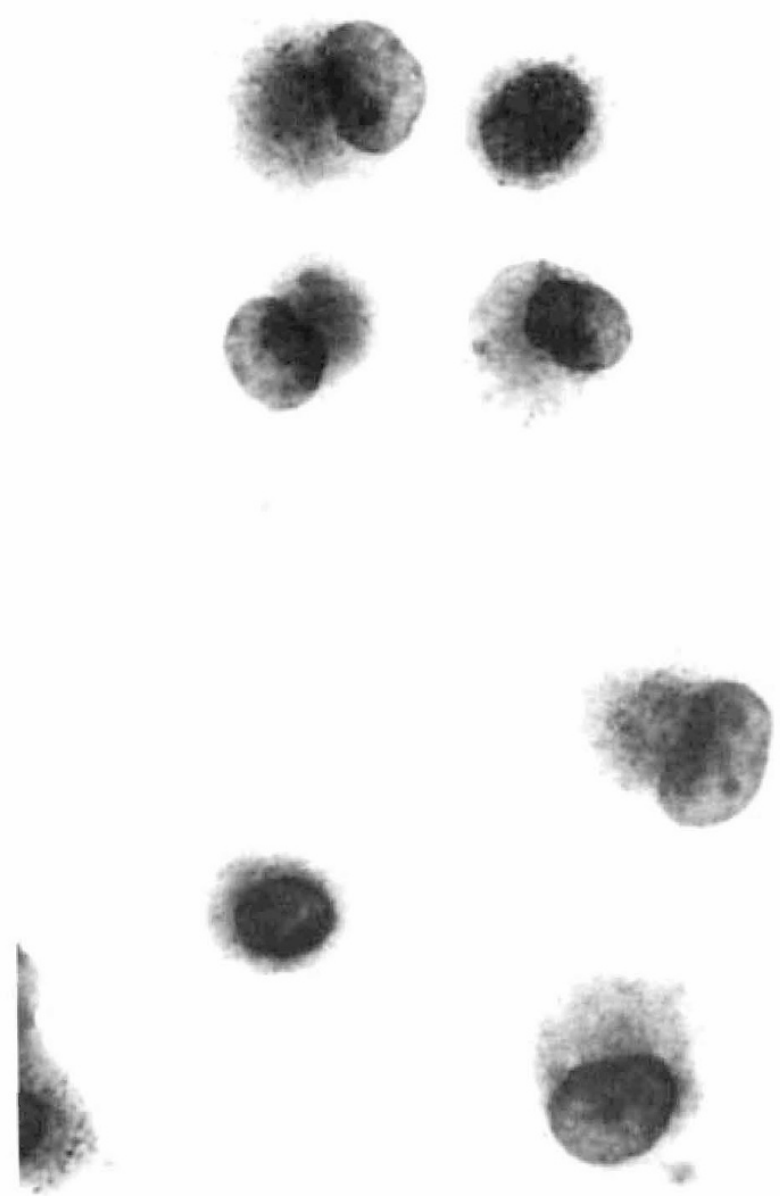

Fig. 1. Photomicrograph of alveolar macrophages from $\mathrm{CF}-1$ cultured for $24 \mathrm{hr}$. The CF macrophages are morphologically indistinguishable from normal alveolar macrophages. $\times 900$.

Table 3. Comparison of Pseudomonas phagocytosis by CF alveolar macrophages in the presence if CF and control serum

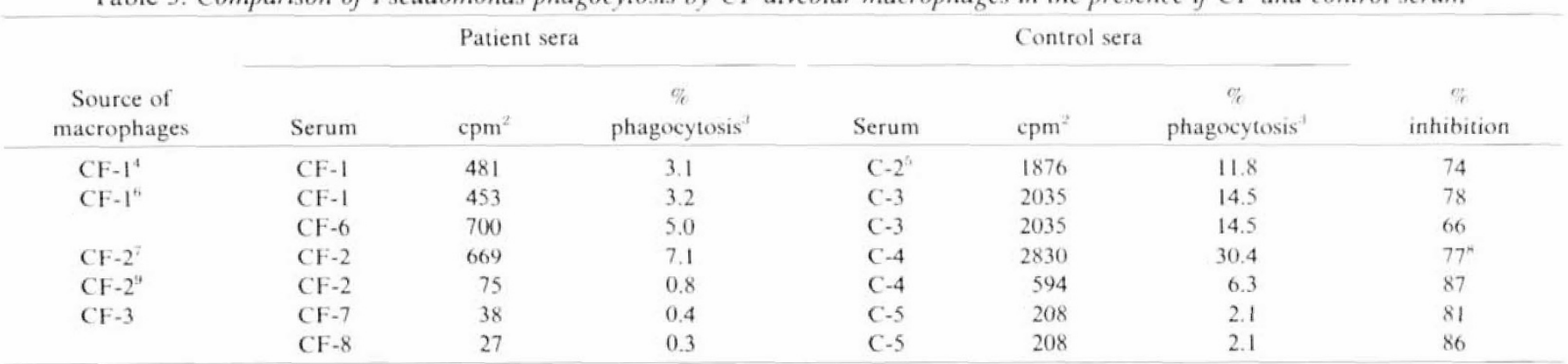

' All assays were carried out with $1 \times 10^{t}$ macrophages except that designated by footnote 8 .

$2 \mathrm{cpm}$ in $0.1 \mathrm{ml}$ aliquot of $1 \mathrm{ml}$ lysate.

"Percentage of radioactive organisms engulfed in $30 \mathrm{~min}$ (see "Materials and Methods" for details)

${ }^{4}$ Cells were cultured $24 \mathrm{hr}$.

${ }^{5} \mathrm{C}$, control.

${ }^{6}$ Cells were cultured $48 \mathrm{hr}$.

${ }^{7}$ First lavage on $\mathrm{CF}-2$.

"These were carried out with $5 \times 10^{6}$ cells.

"Second lavage on CF-2. 
macrophages and were morphologically indistinguishable from normal macrophages.

Because the alveolar macrophages from the $\mathrm{CF}$ patients were all isolated on a Ficoll-Hypaque gradient, the effect of the gradient on cells from a normal volunteer was evaluated. Table 2 shows the results. The gradient had no effect on Pseudomonas phagocytosis by normal alveolar macrophages.

Table 4. Comparison of inhibition of Pseudomonas phagocytosis by normal and $C F$ alveolar macrophages

\begin{tabular}{ccc} 
Serum & $\begin{array}{c}\text { Normal alveolar } \\
\text { macrophages }\end{array}$ & alveolar macrophages \\
source & $88^{2}$ & $76^{3}$ \\
\hline CF-1 & $76^{\circ}$ & 66 \\
CF-6 & 80 & 81 \\
CF-7 & 70 & 86 \\
CF-8 & &
\end{tabular}

${ }^{1}$ All assays were carried out with $1 \times 10^{6}$ macrophages except those designated by footnote 2 .

2 These were carried out with $5 \times 10^{5}$ cells.

"Average of two experiments.
PHAGOCYTOSIS OF P. AERUGINOS.A

Table 3 shows the Pseudomonas phagocytosis results of cells from the $3 \mathrm{CF}$ patients (CF-1, CF-2, and CF-3) from whom alveolar macrophages were successfully isolated. All of the CF cells were able to phagocytize Pseudomonas in the presence of normal serum, but phagocytosis was inhibited in the presence of autologous or heterologous CF serum. Although variation occurred in the percentage of phagocytosis, the percentage of inhibition was rather constant. This is shown clearly in the case of CF-2. Two lavages were performed on this patient. Cells from the first lavage phagocytized at a high level $(7.1 \%$ in presence of CF serum and $30.4 \%$ in presence of normal serum), whereas the cells from the second lavage exhibited a lower level $(0.8 \%$ in CF serum and $6.3 \%$ in normal). However, on comparison of the percentage of inhibitions there is little difference (77\% for the cells of the first lavage and $87 \%$ for those of the second lavage).

The percentage of inhibition of Pseudomonas phagocytosis by $\mathrm{CF}$ and normal alveolar macrophages in the presence of $\mathrm{CF}$ serum is compared in Table 4. CF serum extensively inhibited phagocytosis in both normal cells and CF cells.

\section{PHAGOCYTOSIS OF S. AUREUS}

Phagocytosis of $S$. aureus by both $\mathrm{CF}$ and normal macrophages is shown in Table 5. In contrast to Pseudomonas phagocytosis, CF

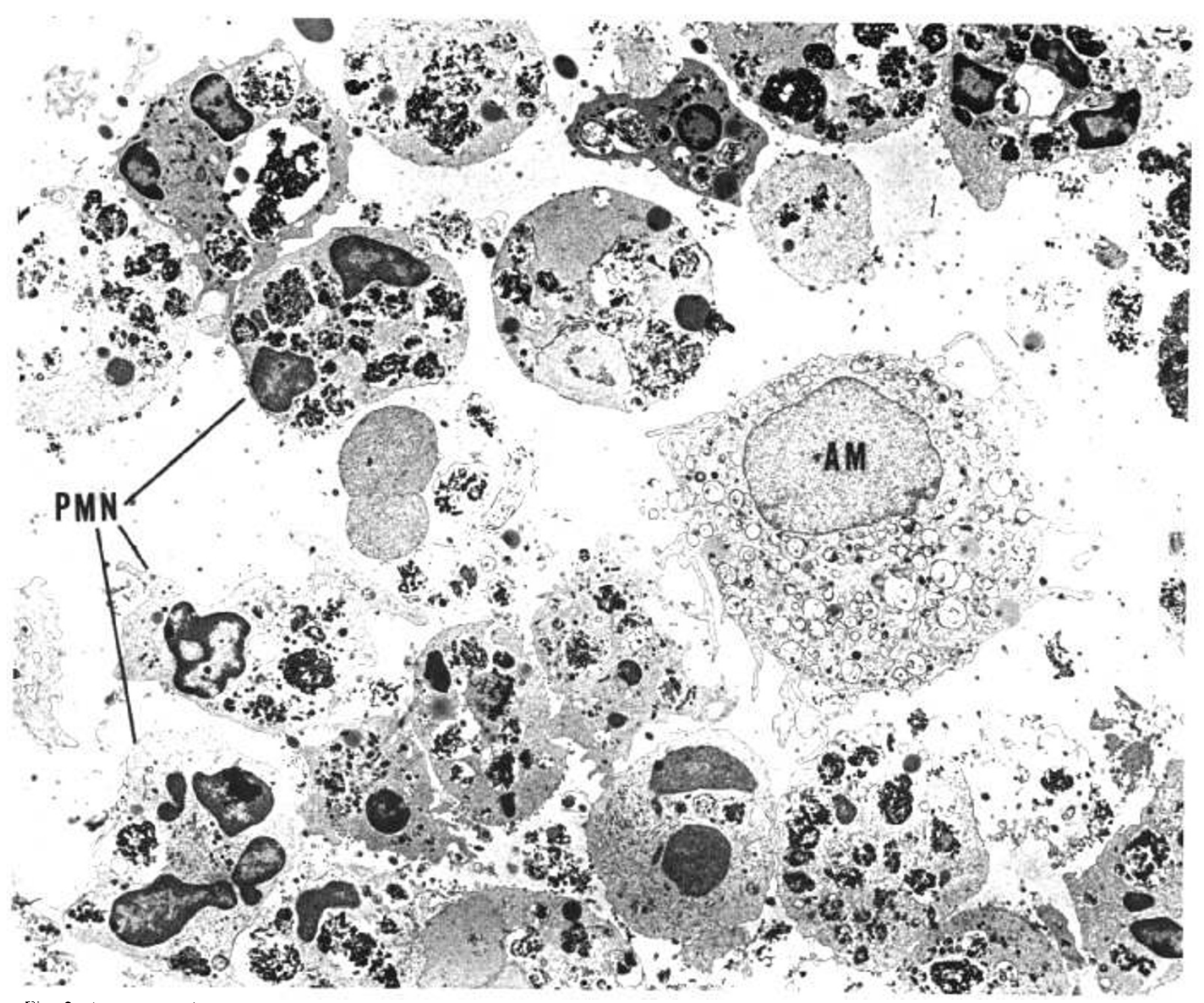

Fig. 2. A representative area from a cell pellet derived from the lavage fluid of $(F-2$. An alveolar macrophage ( $A M$ ) at the center right is surrounded by a large number of partially degenerated PMN's. $\times 2000$. 
and normal macrophages show little difference in their ability to phagocytize $S$. aureus either in the presence of $\mathrm{CF}$ or normal serum.

\section{FLECTRON MICROSCOPY}

Cellular pellets obtained from CF lavage fluid by centrifugation consisted of macrophages and PMN's (Fig. 2). The latter cells were heavily engaged in phagocytosis as shown by their abundant dense phagosomes. Many of these cells were in various stages of degeneration. The macrophages (Fig. 3) showed a spectrum of organelles and inclusions. Representative cells possessed a moderate number of phagosomes containing myelin figures and some primary lysosomes. Similarly, macrophages (Fig. 4) from normal donors had a moderate number of phagosomes and lysosomes. No discernible difference was evident between CF and normal alveolar macrophages.

\section{DISCUSSION}

The host-parasite relationship in CF pulmonary disease is complex. It is a cycle that apparently begins with the pulmonary obstruction that is inherent in the disease. This leads to infection and inflammation, which cause further obstruction, resulting in increased infection. The end result is progressive lung damage. Once started, this cycle is difficult to interrupt.

Because control of pulmonary infection is dependent on the efficient functioning of alveolar macrophages (5), it is important to assess their competence in CF patients and factors which affect them. The data presented indicate that in some infected CF patients viable and functional alveolar macrophages can be isolated and that the phagocytic properties of these cells are similar to cells from normal individuals. However, Pseudomonas phagocytosis by these CF macrophages and those from normals is inhibited by $C F$ serum. In contrast, CF serum does not inhibit the phagocytosis of $S$. aureus by either CF or normal cells.

The role of $S$. aureus in the progression of the pathophysiology of CF pulmonary infection is unclear. Most patients are colonized initially with $S$. aureus but later Pseudomonas emerges as the predominant pathogen. Although the phagocytosis of $S$. aureus by CF and normal macrophages appears to be the same, additional experiments comparing $\mathrm{CF}$ and normal cells in the presence of the same serum samples are needed to fully evaluate the phagocytosis of $S$. aureus. In general, the percentage of phagocytosis of $S$. aureus appears low. However, the strain used in these experi-

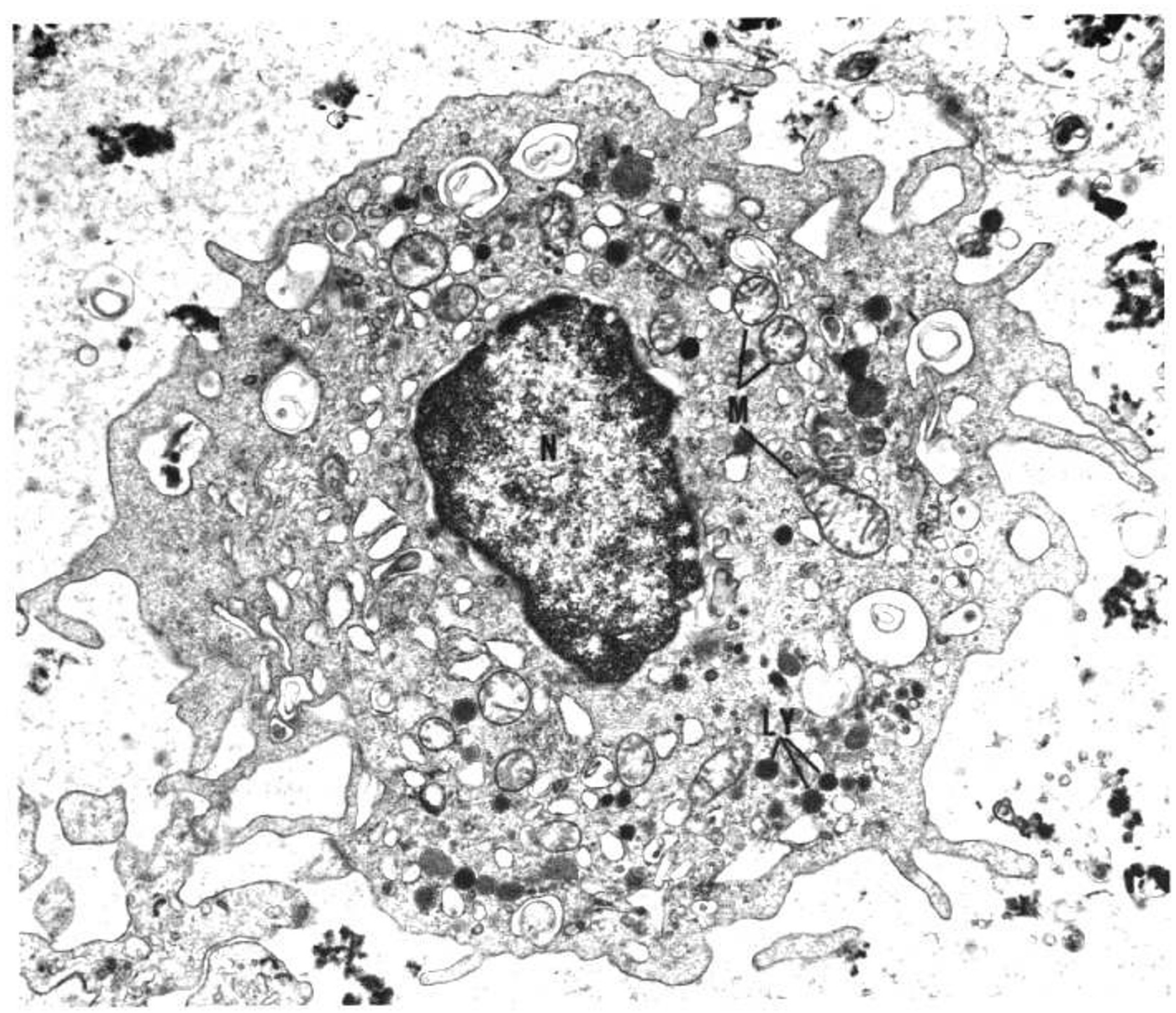

Fig. 3. An alveolar macrophage from $(\mathrm{F}-2$. The cytoplasm contains a number of myelin figures in vacuoles, some primary lysosomes $(L Y$ ), a modest number of mitochondria $(M)$, and abundant cytofilaments. The cell debris that surrounds the macrophage is primarily of $P M N$ origin. $\times 7800$. 
Table 5. Comparison of $S$. aureus phagocytosis by $C F$ and normal alveolar macrophages in the presence of $C F$ and control serum ${ }^{1}$

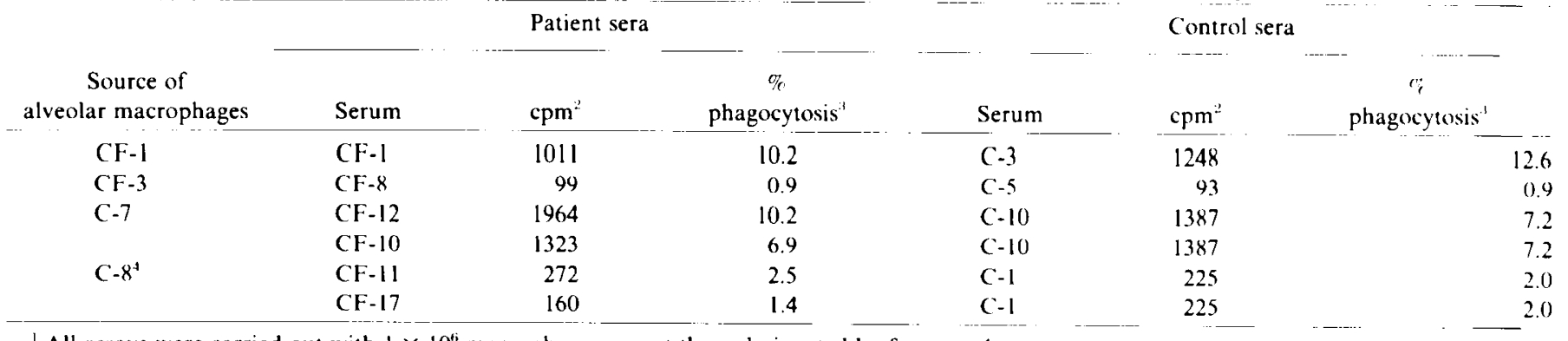

' All assays were carried out with $1 \times 10^{\text {in }}$ macrophages except those designated by footnote 4 .

cpm in $0.1 \mathrm{ml}$ aliquot of $1.0 \mathrm{ml}$ lysate.

"Percentage of radioactive organisms engulfed in $30 \mathrm{~min}$ (see "Materials and Methods" for details).

${ }^{4}$ These were carried out with $5 \times 10^{5}$ cells.

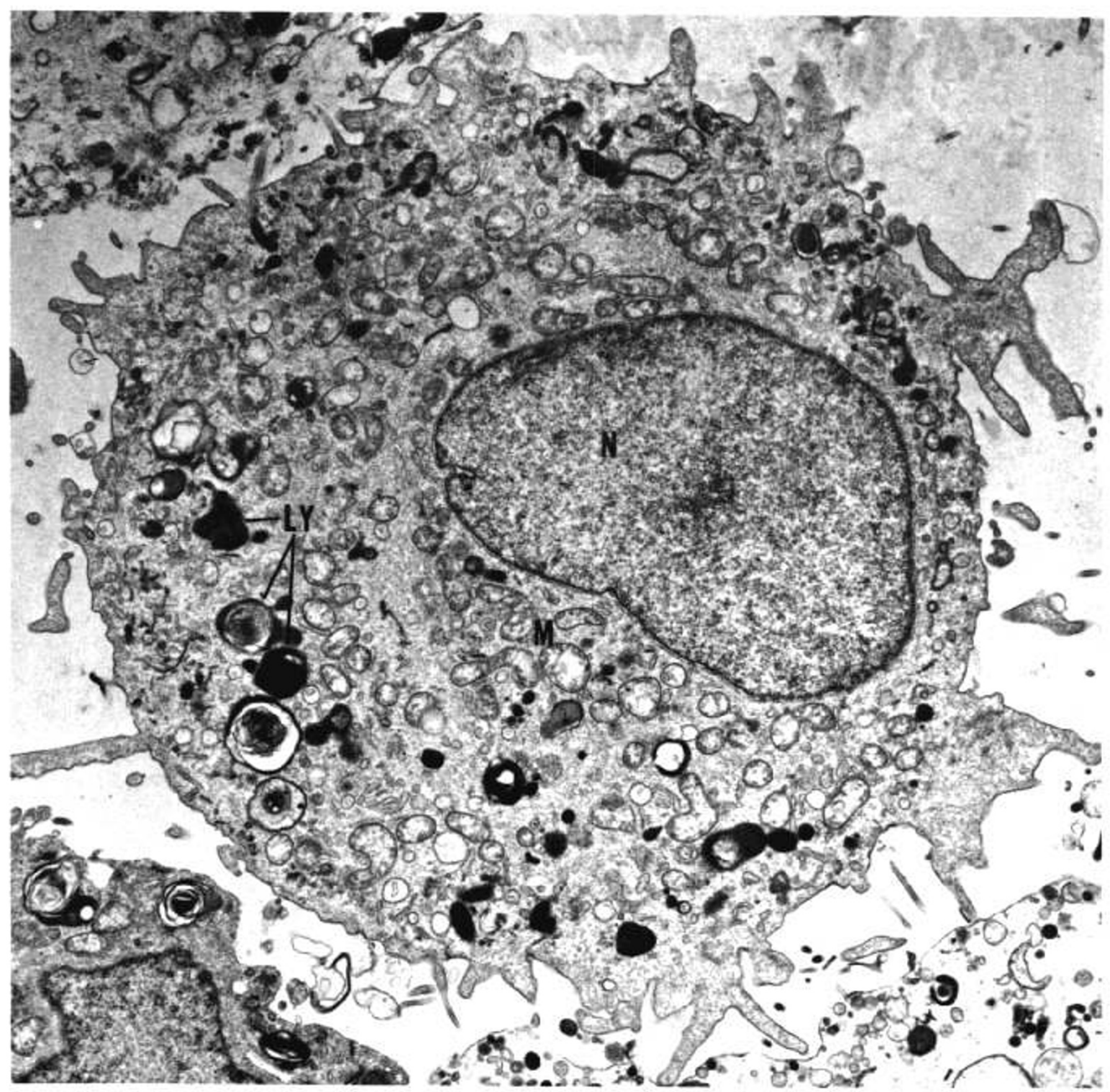

Fig. 4. An alveolar macrophage from a normal donor. Such macrophages closely resemble those found in CF patients. $\times 11,000$. 
ments was a CF clinical isolate, and according to Hoiby (6), all CF $S$. aureus isolates have protein A, which is antiphagocytic. That this may account for the low level of phagocytosis is supported by the observation that rabbit alveolar macrophages show a five-fold increase in phagocytosis when $S$. aureus strain Wood 46 (lacking protein A) is compared to $S$. aureus strain Cowan 1 (containing protein A) (18).

Experience with lavage fluid from $5 \mathrm{CF}$ patients indicates marked differences in cellular composition, apparently related to clinical condition. Patients in poorer condition with greatly decreased pulmonary function had fewer macrophages. This may be related to the fact that the alveolar macrophage does not function under conditions of low oxygen tension (1). The PMN alone is not able to control infection and requires the macrophage to "clean up." When the macrophage is not present, the degenerating PMN may actually increase the lung damage and contribute to the pathophysiology of the disease. The exclusion of trypan blue by cells from the lavage fluid appears to over estimate the number of viable cells because both light and electron microscopy indicate a considerable number of degenerating PMN's. When isolated from patients in better condition, CF macrophages were shown to be viable and functional in vitro by their ability to adhere to glass and to phagocytize in the presence of normal serum.

The in vitro phagocytic function of the CF macrophage toward Pseudomonas appears to be altered by an inhibitory activity present in $\mathrm{CF}$ serum (17). The ultrastructural studies do not suggest any increase of in vivo phagocytosis by CF alveolar macrophages when these cells are compared to those from uninfected normals. Specifically, the CF macrophages showed no evidence of bacterial phagocytosis, and the number, size, and contents of their phagosomes were identical to those from normal donors. In contrast, PMN's from CF patients with Pseudomonas infection were clearly engaged in extensive phagocytic activity. The normal morphology and the in vitro studies in the presence of normal serum indicate a normal phagocytic potential, and yet the macrophages do not appear to have been heavily engaged in phagocytosis as would be expected with chronic infection. These observations suggest that inhibition of Pseudomonas phagocytosis may also be occurring in vivo.

Although the alveolar macrophage originates from the same stem cell as macrophages in other parts of the body, it has unique morphologic and enzyme characteristics and responds differently to environmental conditions (12). The other phagocytic cells of the CF patient appear to be able to control infection because sepsis is a rare occurrence in CF even in the terminal stages (19). This is in a sharp contrast to burn patients, cancer patients, and immunosuppressed individuals who rapidly develop septicemia when infected with Pseudomonas (19).

The unusual pulmonary susceptibility of the CF patient to a ubiquitous, normally nonpathogenic organism is an unexplained phenomenon. We have demonstrated that CF alveolar macrophages can function normally in a suitable environment but that CF serum contains an activity that specifically inhibits Pseudomonas phagocytosis by $\mathrm{CF}$ as we!l as normal alveolar macrophages. Pulmonary lavage fluid is known to contain many serumderived components (13). Thus, the chronic pulmonary infection of CF may be due to an extrinsic factor in an altered lung

Copyright $(1980$ International Pediatric Research Foundation. Inc. $0031-3998 / 80 / 1405-0715 \$ 02.00) / 0$ environment and does not appear to be related to an intrinsic cellular defect of the macrophage. Although not conclusive, data presented in the previous report (17) suggest that the seruminhibitory activity may be acquired as a result of Pseudomonas infection. Studies are in progress to determine if this inhibitory activity is present in lavage fluid from patients with $\mathrm{CF}$ and other chronic obstructive lung diseases. Characterization and identification of this activity may indicate ways of altering the hostparasite relationship in the CF pulmonary tract.

\section{REFERENCES AND NOTES}

1. Cohen, A. B., and Cline. M. J.: The human alveolar macrophage; isolation, cultivation in vitro, and studies of morphologic and functional characteristics. J. Clin. Invest., 50: 1390 (1971).

2. Doershuk. (.. F., and Matthews, L. W.: (ystic fibrosis and obstructive pulmonary disease. In: M. Green, R. J. Haggerty: Ambulatory Pediatrics. p. 107 (W. B. Saunders (ompany. Philadelphia, 1968)

3. Doershuk. C. F.. Matthews. L. W.. Tucker. A. S.. and Spector, S.: Evaluation of a prophylactic and therapeutic program for patients with cystic fibrosis. Pediatrics, 36: $675(1965)$

4. Fisher, M. W.. Devlin. H. B.. and Gnabasek, F. J.: New immunotype schema for Pseudomonas aeruginosa based on protective antigens. J. Bacteriol., 98: 835 $(1969)$.

5. Green. G. M., and Kass, E. H.: The role of the alveolar macrophage in the clearance of bacteria from the lung. J. Exp. Med., 11\%: 167 (1964).

6. Hoiby. N.: Pseudomonas aeruginosa infection in cystic fibrosis. Acta Pathol. Microbiol. Scand. Suppl. C, 262: 1 (1977).

7. Homma. J. Y.. Shinonya. H., Yamada, H.. Kawabe, Y.: Production of antibody against Pseudomonas aeruginosa and its serological typing. Jpn. J. Exp. Med.. 41: $89(1971)$.

8. Karnovsky, M. J.: A formaldehyde-glutaraldehyde fixative of high osmolality for use in electron microscopy. J. Cell Biol.. 27: 137A (1965).

9. Koski, I. R., Poplack. D. G.. and Blaese. R. M.: A nonspecific esterase stain for the identification of monocytes and macrophages. In: B. R. Bloom. J. R. David: In vitro methods in cell-mediated and tumor immunity. pp. 359-362 (Academic Press, Inc. New York, 1976).

10. Millonig. $\mathrm{G}$.: Advantages of a phosphate buffer for $\mathrm{O}_{\mathrm{s}} \mathrm{O}_{4}$ solutions in fixation. $\mathrm{J}$. Appl. Physiol.. 32: 1637 (1961).

11. Millonig. (;: A modified procedure for lead staining of thin sections. J. Biophys. Biochem. Cytol., 11:736 (1961).

12. Pearsall. N. N.. and Weiser, R. S.: Macrophage metabolism. In: The Macrophage pp. 41-56 (Lea \& Febiger. Philadelphia, 1970).

13. Reynolds. H. Y.. and Newball, H. N.: Analysis of proteins and respiratory cells obtained from human lungs by bronchial lavage. J. Lab. Clin. Med., 84: 559 (1974).

14. Shwachman, H.. Kulczycki, L. L.. and Khan. K. T.: Studies in cystic tibrosis: report of 65 patients over 17 years of age. Pediatrics, 36 : 689 (1965).

15. Stempak. J. G.. and Ward, R. T.: An improved staining method for electron microscopy. J. ('ell Biol., 22: 697 (1964).

16. Tandler, B., and Walter, R. J.: Epon-Maraglas embedment for electron microscopy. Stain Technol., 52: 238 (1977).

17. Thomassen, M. J.. Boxerbaum. B., Demko, C. A.. Kuchenbrod. P. J., Dearborn. D.. and Wood. R. E.: Inhibitory effect of cystic fibrosis serum on Pseudomonas phagocytocis by rabbit and human alveolar macrophages. Pediatr. Res., 1.3: 1085 (1979)

18. Thomassen. M. J., and Demko. C. A.: (unpublished observations)

19. Wood. R. E.: Pseudomonas: The compromised host. Hosp. Pract.. 11: 91 (1976).

20. Wood, R. E. Boat. T. F., and Doershuk, C. F.: State of the art: cystic fibrosis Am. Rev. Respir. Dis.. 1/3: 833 (1976).

21. Different culture vessels were used because of limited availability of chamber slides from the supplier.

22. Requests for reprints should be addressed to: M. J. Thomassen. Ph.D.. Department of Pediatrics. 2101 Adelbert Rd.. ('leveland. OH 44106 (USA).

23. This research was supported by grants from the United Torch of Cleveland, the Cystic Fibrosis Foundation. Cleveland ('hapter, the Ohio Lung Association. and Public Health Service Grants AM 08305, HL 13885, and 5S07 RR 05335. 24. Received for publication March 13, 1979.

25. Accepted for publication August 9, 1979. 